Historia

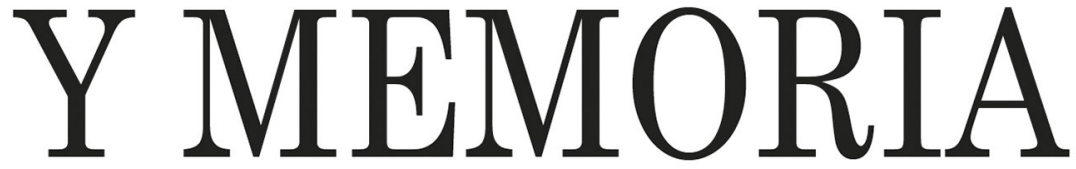

ISSN: 2027-5137 Julio - Diciembre, Año 2016 - Tunja, Colombia

La colección de incunables de la Biblioteca Nacional de Colombia: tras las huellas y vacios de su formación

Robinson López Arévalo Páginas: 85 - 120 DOI: http://dx.doi.org/10.19053/20275137.5201

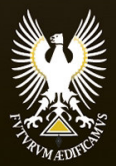




\title{
La colección de incunables de la Biblioteca Nacional de Colombia: tras las huellas y vacíos de su formación*
}

\author{
Robinson López Arévalo ${ }^{1}$ \\ Biblioteca Nacional de Colombia
}

Recepción: 22/10/2015

Evaluación: 22/04/2016

Aprobación: 06/05/2016

Artículo de Investigación e Innovación.

DOI: http://dx.doi.org/10.19053/20275137.5201

\section{Resumen}

Este texto hace un recorrido por la forma en que se reunió la colección de incunables que hacen parte del acervo bibliográfico de la Biblioteca Nacional de Colombia, manifestando cómo han sido sometidos a diferentes organizaciones, sistemas de catalogación y ubicaciones. Factores como: el motivo y momento de la entrada de los libros dan cuenta de la relación que los individuos y las comunidades han tenido con el libro antiguo. Para su elaboración se indagó en los diferentes catálogos e índices que ha tenido la Biblioteca y en los informes de los directores de la misma. Este constituye un primer paso hacia el reconocimiento y la difusión del patrimonio bibliográfico colombiano.

\footnotetext{
* Este trabajo hace parte del esfuerzo que hace la Biblioteca Nacional de Colombia por conocer a mayor profundidad su colección y difundir el patrimonio bibliográfico nacional. [Agradezco los comentarios de José Antonio Amaya, Andrés Felipe Hernández, Sebastian Mejía, Camilo Páez, Alfonso Rubio y Magdalena Santamaría Granda].

1 Historiador de la Universidad Nacional de Colombia. Joven investigador de Colciencias en el año 2011. Desde 2012 trabaja en la Biblioteca Nacional de Colombia desarrollando temas relacionados con la cultura escrita: libro antiguo e historia del libro, de la lectura y de las bibliotecas. Su última publicación se titula «Lecturas útiles y necesarias: oferta del libro en Bogotá, 1870-1886». Correo electrónico: rlopez@ bibliotecanacional.gov.co y robinsonlopeza@gmail.com
} 
Palabras clave: incunable, Biblioteca Nacional de Colombia, patrimonio bibliográfico, libro antiguo.

\title{
The Collection of Incunabula of the National Library of Colombia: Tracks and Silences in its Formation
}

\begin{abstract}
This article tracks the formation of the inculabula collection that forms part of the stock of the National Library of Colombia, manifesting how this collection has been subject to different forms of organization, systems of cataloguing and places. Factors such as: the reason and moment of entry of books account for the relation that individuals and communities have held with ancient and rare books. In order to do this, we examined different catalogues and indexes that the Library has had, as well as the reports presented by its directors. This study constitutes a first step towards the recognition and dissemination of Colombian bibliographical patrimony.
\end{abstract}

Key words: Incunabula, Biblioteca Nacional de Colombia, bibliographical patrimony, rare and ancient books.

\section{La collection d'incunables de la Bibliothèque Nationale de la Colombie: sur les traces et les vides de sa formation}

\section{Résumé}

Ce texte retrace les origines de la collection d'incunables qui constitue une partie du patrimoine bibliographique de la Bibliothèque Nationale de Colombie, en montrant comment elle a été soumise à différents types d'organisation et catalogation. Des facteurs comme les raisons de l'entrée des livres à la Bibliothèque et le moment où celle-là s'est produite rendent compte de la relation que les individus et les communautés ont entretenue avec le livre ancien. Pour l'élaboration de cet article nous avons étudié les différents catalogues de la Bibliothèque ainsi que les rapports rédigés par ses directeurs. Il s'agit de faire un premier pas vers la 
constitution et la diffusion du patrimoine bibliographique colombien.

Mots-clés: incunable, Bibliothèque Nationale de Colombie, patrimoine bibliographique, livre ancien.

\section{Introducción}

¿Qué es un incunable? Se considera la Biblia de Gutenberg o Biblia de las 42 líneas como la primera obra impresa en Occidente a través de tipos móviles, los primeros ejemplares estuvieron disponibles hacia 1454 . El concepto de incunable ${ }^{2}$ es usado para designar los trabajos que fueron impresos entre el momento en que se elaboró dicha Biblia y el año 1500. Albert Labarre, destacado historiador del libro, estima entre treinta mil y treinta y cinco mil el número de ediciones publicadas en el siglo XV, representadas en unos 20 millones de libros. En cuanto al tiraje, menciona que, antes de 1480, era de entre 100 y 150 ejemplares; posteriormente, algunas ediciones alcanzaron los 1000 o incluso 2000, pero el promedio se mantuvo entre 400 y 500, a finales del siglo $\mathrm{XV}^{3}$.

Los incunables guardan entre sus hojas elementos que atestiguan el proceso de construcción del libro impreso, es decir todo el recorrido que llevó a la creación del libro como el objeto que actualmente conocemos, es allí donde reside

2 «Incunabula is the plural of the Latin word incunabulum, a cradle. Evolving from its original meaning, incunabulum came to mean "place of birth" or "beginning." In the world of books, the word incunabula refers to books that were printed using metal type up to the year 1500. The year 1500 is more a cutoff date of convenience, marking the transition from one century to the next, rather than signifying a definitive change in the appearance of books from 1501 onwards. It was actually around 1530 that a transformation in the appearance of books is said to have begun to take place» "What are incunabula?», National Diet Library, acceso el 12 de mayo 2015, http://www. ndl.go.jp/incunabula/e/chapter1/. Para ampliar los puntos de vista sobre el término incunable ver: Albert Labarre, Historia del libro (México: Siglo XXI, 2002), Konrad Haebler, Introducción al estudio de los incunables (Madrid: Ollero \& Ramos Editores, 1995), José Luis Checa, El libro antiguo (Madrid: Acento Editorial, 1999) y Jaime Restrepo, La invención de la imprenta y los libros incunables (Bogotá: Universidad del Rosario, 2014).

3 Labarre, Historia del libro, 80. 
su importancia. Por otro lado, aunque se trate de la misma edición, cada incunable es único, y en su largo existir cada libro ha pertenecido a diferentes personas, ha sido leído por distintos ojos e inscrito por diversas manos; de ahí que su análisis no es el estudio de un objeto, sino de la relación del ser humano y la cultura de la imprenta.

La Biblioteca Nacional de Colombia (de acá en adelante $\mathrm{BNC}$ ) posee 50 títulos incunables, empastados en 36 volúmenes. Esta colección no tiene un mismo origen y su formación obedece a diferentes situaciones históricas: la expulsión de los Jesuitas, la extinción de comunidades religiosas y tal vez alguna donación. Solamente desde la segunda mitad del siglo XIX se empezó a utilizar el término incunable en la BNC y fue solamente hacia 1997 o 1998 cuando se tomó la decisión de agruparlos en un fondo bibliográfico, con la signatura RI -Raros incunables ${ }^{4}$, como se encuentran organizados actualmente. En este texto, para la identificación de los libros, se utilizará la signatura RI en lugar del título ya que cada volumen puede tener varios títulos, como es el caso del RI 3 que contiene 7 obras incunables diferentes; cuando sea utilizada por primera vez la signatura se aclarará entre paréntesis si el volumen tiene más de un título.

La utilidad de este trabajo radica en que aporta nueva información y corrige la que se tenía sobre los incunables, dado que incluye numerosas fuentes que están disponibles gracias al uso masivo de internet. Una labor que está por hacerse es la identificación exacta de los 223 post-incunables (1501-1530) que tiene la BNC, ya que muchos carecen de portada y colofón, y por tanto la fecha de impresión es aproximada, es necesario descartar que entre estos exista un incunable. Si bien, este trabajo se centra en la formación de las colecciones, ya se

4 «En 1998, el sistema base de organización física de la colección general de raros y curiosos, de acuerdo a Dewey, se modificó con el propósito de racionalizar el crecimiento de dicha colección y facilitar el control. Igualmente se modificó el sistema de numeración de la colección de la sala de seguridad». Biblioteca Nacional de Colombia, Colecciones de la Biblioteca Nacional: Tipos y organización física, (Bogotá, Biblioteca Nacional de Colombia, 2001), 4. Aunque, un artículo de Ovalle Mora, publicado en agosto de 1997, ya usa la signatura RI. 
encuentra adelantado el trabajo de catalogación y valoración patrimonial de los libros.

En seguida, se hace un recuento por los estudios pioneros y más importantes sobre los incunables, en Europa y en Colombia; todos ellos orientados hacia la identificación, catalogación y el estudio de cómo han sido armadas las colecciones.

El término incunable fue utilizado por primera vez para definir este tipo de libros en 1640, por Bernhard von Mallinckrodt, en su pequeña obra titulada De ortu et progressu artis typographicae (Del ascenso y progreso del arte tipográfico), en la que también acotó el periodo incunable a los primeros 50 años de la imprenta. Luego, en 1643, Johann Saubert, en su Historia Bibliothecae reipublicae Noribergensis (Historia de la Biblioteca de Núremberg- traducción del autor) dio a conocer el primer inventario de incunables, dando uso continuado al término acuñado por el anterior.

Publicada en 1925, en alemán, la obra titulada: Handbuch der Inkunabelkunde (Introducción al estudio de los incunables) es posiblemente la obra de referencia más importante para el estudio de estos libros. Su autor, Konrad Haebler, trabajó en las bibliotecas de Dresde y Berlín, e hizo parte del grupo que produjo los primeros resultados del Gesamtkatalog der Wiegendrucke (Catálogo colectivo de incunables ${ }^{5}$ - traducción del autor). La trascendencia de la obra se debe a que es la primera que propone, describe y estudia sistemáticamente los elementos más destacados de los incunables: título, autor, colofón, marcas de agua del papel, sellos del impresor, marginalias, registrum, signaturas, columnas, marcas de pertenencia, grabados, etc.; aunque estudios posteriores han corregido algunas de sus aseveraciones ${ }^{6}$.

5 Hoy en día, este proyecto aún está en funcionamiento, su sitio web se llama: Staatsbibliothek zu Berlin. Union Catalogue of Incunabula Database. Acceso el 12 de mayo de 2015, http://www.gesamtkatalogderwiegendrucke.de/GWEN.xhtml.

6 Una actualización de la obra de Haebler es el Manual de incunables, del también alemán Ferdinand Geldner; ambas obras hacen parte de la línea de estudios sobre aspectos técnicos; a diferencia de las obras de Lucien Febvre y Henri-Jean Martin 
La revista alemana Gutenberg Jahrbuch (Anuario Gutenberg - traducción del autor), publicada desde 1926, está dedicada a la historia del libro y de la imprenta; se especializa en primeros impresos y, en la vida y trabajos de Johannes Gutenberg. El Anuario, publicado en Maguncia; ofrece artículos en alemán, francés, inglés, italiano y español; y es entregado a los afiliados de la Gutenberg Society.

En Francia, los trabajos de catalogación de incunables datan de finales del siglo XIX, cuando en 1886, Marie Pellechet empezó la elaboración del Catalogue général des incunables des bibliothèques publiques de France, cuyo primer volumen fue publicado en 1897. La última publicación de la Biblioteca Nacional de Francia: Catalogue des incunables, ofrece una descripción de 12000 incunables en 8000 ediciones diferentes; si bien, el trabajo empezó en 1978, su primer volumen se publicó hasta 1981 y, en 2014, se hizo la última entrega.

La Bodleian Library, en 2005, publicó el Catalogue of Books Printed in the Fifteenth Century now in the Bodleian Library, obra que además de ser un catálogo y manual para clasificar y describir incunables, hace un amplio recorrido histórico sobre cómo fue formada la colección, a través de donaciones y compras, y cómo han sido tratados estos en la Biblioteca. Dicho fondo cuenta con 6700 incunables en 5600 ediciones diferentes. Diez años duró la elaboración del catálogo, que hunde sus raíces en 100 años de trabajo, e incluso más, si se tiene en cuenta que el primer catálogo de la biblioteca fue publicado en 1605, conteniendo una sección dedicada a los incunables. También se destaca el Catalogue of Books Printed in the XVth Century now in the British Library; las tres primeras partes están dedicadas a los incunable alemanes, de la cuarta a la séptima a los italianos, la octava a los franceses, la novena a holandeses, la décima a los españoles y portugueses, la undécima a los ingleses, la duodécima de nuevo a los italianos y la decimotercera a los hebreos; numerosos investigadores

(La aparición del libro), Elizabeth Eisentein (La imprenta como agente de cambio y La revolución de la imprenta en la edad moderna europea) y Rudolf Hirsch (Printing, selling and reading 1450-1500) que tienen un aspecto histórico. 
trabajaron desde comienzos del siglo XX en este catálogo, entre los que se destacan: Robert Proctor, Alfred W. Pollard, Adriaan Offenberg, Lotte Hellinga y Paul Needham.

Julián Martín Abad, elaboró el Catálogo bibliográfico de la colección de incunables de la Biblioteca Nacional de España, en el cual se registran 3158 ejemplares en 2297 ediciones. Esta obra hace un recuento de cómo ingresaron los incunables a la Biblioteca y cómo han sido catalogados y agrupados, a lo largo de tres siglos.

Colombia cuenta con una breve bibliografía sobre el tema, a continuación se mencionan sus elementos más representativos. La obra Cinco incunables en la biblioteca general de la Universidad de los Andes da cuenta de los libros que fueron donados a esta Universidad, por el chileno Oswaldo R. Buckle, en $1975^{7}$. Es un texto orientado hacia la difusión, si bien no deja de lado el análisis bibliográfico del libro antiguo. Los estudios incluidos tienen una biografía del autor, una nota sobre el editor, una reseña de la obra y una descripción de la estructura de los libros. La obra no informa sobre las inscripciones manuscritas y el recorrido de los incunables antes de ser adquiridos por Buckle.

En 1982, el Banco de la República, editó el primer catálogo de incunables hecho en Colombia, titulado Incunables de la Biblioteca Luis Ángel-Arango del Banco de la Repúblicas. Esta obra sigue los lineamientos tradicionales de los estudios bibliográficos al revisar los 33 incunables que tiene la Biblioteca, contiene además la transcripción de algunas páginas y las biografías de unos cuantos autores. También incluye reproducciones de algunas partes importantes, como la portada, el colofón y las letras capitales ilustradas. No siempre aclara si el incunable tiene alguna marca de posesión, inscripciones manuscritas o capitulares miniadas.

$7 \quad$ María Victoria Franco, Cinco incunables en la biblioteca general de la Universidad de los Andes (Bogotá: Universidad de los Andes, 1980).

8 Biblioteca Luis Ángel Arango, Incunables de la Biblioteca Luis Ángel-Arango del Banco de la República (Bogotá: Litografía Arco, 1982). 
En 2010, Villegas editó El libro de los libros9, este es un intento por difundir los atributos visuales más representativos del libro antiguo, no es un texto para especialistas y tampoco un catálogo; su fuerza está en el impacto visual que genera en quien se acerca por primera vez al tema. De los dos volúmenes que la componen, apenas dedica unas páginas para mostrar las características más destacadas de 6 de los 12 incunables que posee la Biblioteca de la Universidad Javeriana.

En la misma línea, dar a conocer al público lego las obras más importantes que poseen, se encuentra el título Tesoros del Colegio Mayor de Nuestra Señora del Rosario ${ }^{10}$. Se reseñan 4 de los 12 incunables que se resguardan entre sus colecciones institucionales, con más énfasis en lo visual que en lo bibliográfico. La invención de la imprenta y los libros incunables ${ }^{11}$ es una obra que estudia los incunables de la Universidad del Rosario, es sin duda la más completa dentro de este grupo de libros dedicados al tema, en el entorno nacional. Casi la mitad del libro se ocupa de hacer un repaso sobre el desarrollo histórico del libro, desde la antigüedad hasta el siglo XV; además de enumerar y definir las características más importantes de los incunables utilizando una bibliografía destacada. La parte dedicada a los incunables de la Universidad es en parte catálogo, descripción profunda y análisis de sus usos; incluyendo los más mínimos detalles.

En 1924, Marco Fidel Suarez le obsequió al Concejo de Cúcuta como agradecimiento por el apoyo recibido durante su gobierno, un ejemplar, en pergamino, del Liber Cronicarum, impreso en Núremberg por Anton Koberger, en 1493. En Cúcuta, se han escrito dos obras relacionadas con

$9 \quad$ Benjamín Villegas, dir. El libro de los libros: bibliotecas Pontificia Universidad Javeriana (Bogotá: Villegas Editores y Universidad Javeriana, 2010).

10 Hans-Peter Knudsen et. al, Tesoros del Colegio Mayor de Nuestra Señora del Rosario: 350 años (Bogotá: Villegas Editores, 2003).

11 Restrepo, La invención de la imprenta. Muy seguramente esta obra sirvió de base para elaborar el sitio web dedicado al libro antiguo y, en especial, la sección dedicada a incunables: Universidad del Rosario, Clásicos UR, Los incunables de la Biblioteca Antigua del Colegio Mayor del Rosario, acceso el 12 de mayo 2015, http:// clasicosarchivohistoricour.org/tag/incunables/ 
este incunable. La primera: Una mirada al libro Crónicas de Núremberg, Incunable propiedad de la ciudad de Cúcuta ${ }^{12}$ hace un pequeño recuento por los aspectos más importantes del incunable y reproduce varios de los grabados de este libro. En la segunda: Monstruos y prodigios, y Rameras y esposas ${ }^{13}$, fueron copiados textos de varios libros antiguos y grabados del mismo incunable; intentando hacer una reflexión sobre cómo han sido tratadas las temáticas de su título en el material bibliográfico; su objetivo principal es la difusión y apropiación de la obra.

En general, las obras producidas en Colombia sobre incunables pretenden catalogar de manera más o menos exhaustiva los incunables. Si bien, no dan cuenta de información valiosa para su análisis, por ejemplo: cómo fueron formadas las colecciones, los usos del libro, los nombres de los propietarios, la ubicación en otras bibliotecas, la unicidad de la obra y las temáticas. En verdad, son unos primeros intentos orientados a la difusión de estos corpus y del conocimiento contenido en ellos.

El presente artículo no es un catálogo de los incunables, ya que a la fecha los registros están disponibles en línea a través del catálogo bibliográfico de la BNC. Tampoco está enmarcado dentro de los trabajos específicos sobre impresores, tipos de letras, papel, filigranas, etc. Este texto pretende describir, hasta donde se ha podido, cómo se formó la colección de incunables de la BNC, y reconstruye la forma en que estos libros han sido tratados: usos, catalogaciones, agrupaciones, pérdidas, etc. Su principal cualidad como trabajo académico reside en un intento por metodizar el conocimiento sobre este tipo de libros, para de esta manera facilitar su difusión y acceso como parte del patrimonio bibliográfico nacional.

12 Centro cultural de la Alcaldía de Cúcuta, Una mirada al libro Crónicas de Nuremberg, Incunable propiedad de la ciudad de Cúcuta (Cúcuta: Talleres Gráficos de La Opinión, 1998).

13 Juan Carvajal, ed., Monstruos y prodigios en el Liber Cronicarum incunable de la biblioteca JPF de San José de Cúcuta. ([Cúcuta]: Ediciones Heredita, [2008?]). Juan Carvajal, ed., Rameras y esposas: en el Liber Cronicarum incunable de la biblioteca JPF de San José de Cúcuta (San José de Cúcuta: Ediciones Hederieta, [2010?]). 
Para la elaboración de este trabajo se utilizaron los viejos catálogos en papel que posee la $\mathrm{BNC}$, algunas fuentes secundarias digitalizadas disponibles a través de la web, el Catálogo de la Biblioteca del Congreso de los Estados Unidos (Library of Congress Online Catalog), el Catálogo de la Biblioteca Británica (en especial su sección dedicada a los incunables, llamada Incunabula Short Title Catalogue, de acá en adelante ISTC), el acervo de incunables digitalizados por la Biblioteca Estatal de Baviera (Bayerische Staatsbibliothec), y la sección de incunables de la página web de la National Diet Library. Los mismos incunables, con sus rastros de lectores y de poseedores, se convirtieron en una importante fuente de información para descubrir los orígenes de la colección.

\section{Los incunables de la biblioteca fundacional}

Por Biblioteca fundacional se entiende aquella colección de obras recolectadas tras el secuestro hecho por la corona española a los bienes a la Compañía de Jesús, con las cuales se conformó la Real Biblioteca Pública de Santafé, en 1777.

Revisar el Inventario de la Biblioteca Común del Colegio Máximo de la Compañía de Jesús de Bogotá fue la primera tarea para identificar los incunables que se encontraban registrados en el inventario más antiguo que tiene la $\mathrm{BNC}$. El trabajo resultó complicado dado que los registros del Inventario solo incluyen el autor, la cantidad de tomos, el tamaño y el tipo de encuadernación; carecen del año de impresión, del nombre del impresor, y en general, los datos muchas veces son vagos y ambiguos ${ }^{14}$.

El único incunable que se ha podido identificar con seguridad en este inventario es Summa que destructorium viciorum apellat, perteneciente a la sección "Moraliste", y que actualmente lleva la signatura RI 35. Es posible que el RI 3

14 Un intento por identificar con exactitud cada uno de los títulos referenciados en el Inventario lo hizo José Del Rey Fajardo en su obra La biblioteca colonial de la Universidad Javeriana de Bogotá; aunque, la obra tiene algunas inconsistencias y deja abiertas muchas preguntas. 
(siete títulos) esté referenciado en el Inventario como "ITEM. Otro Arte. Un tomo en octava, de pergamino al num ${ }^{\circ} 2$ ", es el único $\mathrm{Arte}^{15}$ que se encuentra en la BNC; hace parte de la sección Gramáticos. El RI 17 (dos títulos), muy probablemente está en la sección "Concionatores" (predicadores), bajo el siguiente registro: "Jacobus de Vorágine Sermones de tempore per totum anni circulum. 1 tomo $8^{\mathrm{a}}$, pergamino, $\mathrm{n}^{\circ} 6^{\prime \prime}{ }^{16}$. Como se puede apreciar los incunables estaban organizados dentro de los grupos temáticos como el resto de la colección, y no tenían un trato especial. El RI 2 no se encuentra en el Inventario, es curioso que tenga un exlibris de la Compañía de Jesús de Bogotá, de la Biblioteca Pública y de los Franciscanos, sin embargo, no queda claro en qué momento perteneció a cada comunidad.

Dadas las limitaciones que ofrece el Inventario de la Biblioteca Común, una salida fue buscar los exlibris o marcas de propiedad existentes en las obras, ya fueran firmas, notas o sellos. Se debe aclarar, que una parte de las marcas de propiedad fueron tachadas, arrancadas o se perdieron con el tiempo, por tanto solo se tuvo en cuenta la información que se pudo leer claramente. Los que tienen el exlibris de la Compañía de Jesús son: RI 1, RI 2, RI 3, RI 17 y RI 35. El RI 1 venía de Tunja por tanto no podía estar en este Inventario que está elaborado solo con los libros del Colegio Máximo de Bogotá.

Contando cada pieza de los volúmenes, en total 12 títulos incunables pertenecieron a la Compañía de Jesús, es decir hacen parte de los libros expropiados tras la expulsión de 1767.

15 Se conocía como Arte a la obra: Aelii Antonii Nebrissensis gramatici introductionum latinarum o Introducciones latinas.

16 Antonio De Verasttegui y Francisco Antonio Moreno. Inventario de la Biblioteca Común del Colegio Máximo de la Compañía de Jesús. Santafé de Bogotá: Real Biblioteca de Santafé. $1766-1767$, f. 150 verso $§ 24$, f. 72 recto $§ 16$, f. 33 verso $§ 8$. 


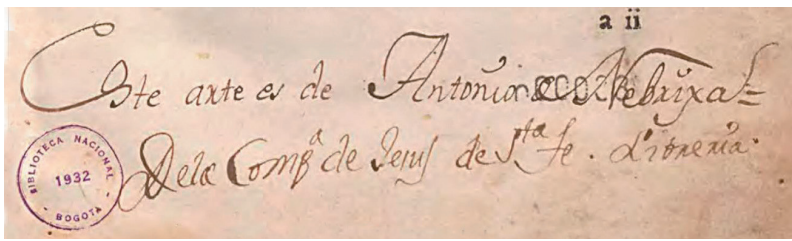

Imagen 1. Marca de pertenencia a la Compañía de Jesús de Santa Fe, Librería. Fuente: Tomado de Elio Antonio de Nebrija. Aelii Antonii Nebrissensis gramatici introductionum latinarum. Burgos: Fadrique de Basilea, 1496 (RI 3, pza. 1).

\section{Los incunables en la Real Biblioteca}

Cuatro incunables ingresaron a las colecciones de la BNC cuando aún existía la Real Biblioteca Pública de Santafé, pero no tienen marca alguna que indique que pertenecieron a la Compañía; estos son: el RI 13, el RI 15 (dos títulos) y el RI 36. Mientras que, el RI 36 está en el Índice general de libros que tiene esta Real Biblioteca pública de la ciudad de Santafée ${ }^{17}$, en la sección Canonistas; al igual que en el anterior Inventario los incunables estaban organizados dentro de los grupos temáticos. De los libros que pertenecieron a los Jesuitas el RI 1 y el RI 35 no fueron encontrados en este Índice general; el RI 13 tampoco aparece registrado en el Índice. Es importante anotar que se desconoce la procedencia de las obras y el momento exacto de su inclusión dentro de la colección, si bien el periodo de ingreso tuvo que ser entre 1777 y 1819 , es decir entre la apertura de la Real Biblioteca y la salida de los españoles de Bogotá.

\section{En 1796, Manuel del Socorro Rodríguez escribió}

[...] deseando el actual bibliotecario de esta capital ver que años tenía el libro más antiguo de los existentes en la Real Biblioteca (...) halló tres que quizá son los más antiguos que pueden encontrarse en toda América (...) uno cuyo autor, título y fecha son los que transcribimos: Joan Valensis Ordinis

17 Biblioteca Nacional de Colombia, «Índice general de libros que tiene esta Real Biblioteca pública de la ciudad de Santafé», (Bogotá, [1790]?), f. 54 recto §10. El índice es un modelo español, para la Real Biblioteca de España existió uno dedicado solo a los incunables y libros raros, titulado: Índice chronólogico de las ediciones del Siglo XV $y$ algunas de principios del siglo XVI: Sala $3^{a}$ de la Real Biblioteca, pieza typográfica, elaborado con posterioridad a 1736. (Julián Abad, Catálogo bibliográfico de la colección de incunables de la Biblioteca Nacional de España. Vol. I (Madrid: Biblioteca Nacional de España, 2010), XIX). 
Fratrum Minorum. De Regimine Vitae Humanae. Impress. Venetiis, Anno Domini M.CCCC.XCVI. Otro impreso en Nuremberg el mismo año de 1496, su autor Antonio Koberger, y su título: Summa que Destructorium viciorum appellatur ${ }^{18}$.

Se refiere el bibliotecario al RI 01 y al RI 35, en este último confunde el impresor con el autor. También, a pesar de que habla de tres libros solo mencionó $\operatorname{dos}^{19}$.

\section{Los incunables en la República}

En el Índice alfabético de los libros de la Biblioteca Pública de la ciudad de Santa Fe de Bogotá ${ }^{20}$ aparecen los doce incunables que pertenecieron a la Compañía de Jesús y los cuatro que entraron cuando aún existía la Real Biblioteca de Santafé. Este catálogo presenta innumerables problemas para la identificación de las obras. Por ejemplo, aunque en su mayoría están en orden alfabético por el apellido del autor, algunas veces se alfabetizó por el nombre. Otras veces las obras no están en la sección que deberían estar, verbigracia: la obra de Valensis Joannes (RI 1) aparece en la sección de Literatura cuando debería estar en Moralistas; el Arte de Nebrija (RI 3-pza. 1) también aparece en Moralistas cuando debería estar en Gramática. En otras ocasiones se obvio el nombre del autor y se alfabetizó por el título de la obra, como es el caso de la obra Summa casuum conscientiae (RI 2), conocida como Rosella casuum, la cual está en la sección Biblia y sus expositores en la letra R -por Rosellacuando debería estar en la S-por Salis-. Se confundía el nombre de los autores con otro personaje mencionado en el libro; por ejemplo, el Liber ad Almansorem sive Tractatus medicinae I-X (RI 15-pza. 1) es atribuido a Hieronymus de Manfredis pero su

18 Manuel del Socorro Rodríguez, "Sigue el discurso empezado en el $\mathrm{n}^{\circ}$ anterior», Papel periódico de la Ciudad de Santafé de Bogotá, Bogotá, 19 de agosto de 1796, 1544-45.

19 Posiblemente se refiera a: Joannes de Sancto Geminiano. Sermones funebres: eruditissimi viri Fratris Joannis de Sancto Geminiano Ordinis Fratrû Predicatoû verbi divini declamatoribus. Antonii Vincentii, 1536 (RV 77); obra con nota manuscrita de Manuel del Socorro: «Según la fecha de la dedicatoria (año 1499) viene a tener la edición de este libro 292 años en el presente de 1793».

20 Biblioteca Nacional de Colombia, Índice alfabético de los libros de la Biblioteca pública de la ciudad de Santa Fe de Bogotá, (Bogotá, 1823). 
autor es Rhasis Mohammed. Al igual que sucedió a Manuel del Socorro Rodríguez se trocó el autor de Summa que destructorium viciorum apellat con su impresor, entonces aparece en la letra $\mathrm{K}$ de Kobergerg y no en la $\mathrm{C}$ de Carpentarius. En otro caso, la primera letra del apellido del autor de Opera medica (RI 13) Guainerius Antonius, es cambiada por una S, de tal forma que se convirtió en Suainerio. Por último, los registros no tienen el año de impresión, como ocurre con Repertorium de pravitate haereticorum (RI 36).

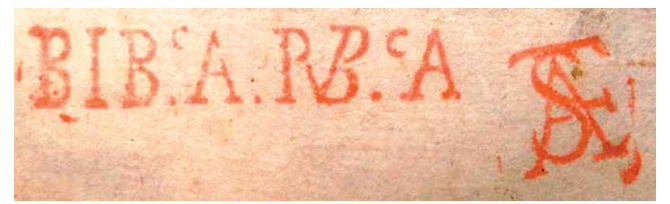

Imagen 2. Sello y monograma de la Biblioteca Pública de Santa Fe (RI 1) ${ }^{21}$ Fuente: Tomado de Valensis Joannes. Summa Ioannis Valensis de regimine vitae humane. Venecia: Georgius de Arrivabenus, 1496.

Distribuyendo los libros según las categorías divisorias utilizadas en el inventario de 1767, y los índices de 1777 y 1823, estos se clasificarían en las siguientes temáticas:

\begin{tabular}{|l|c|}
\hline \multicolumn{1}{|c|}{ Tema } & Cantidad \\
\hline Gramáticos & 7 \\
\hline Médicos & 3 \\
\hline Moralistas & 3 \\
\hline Predicables & 2 \\
\hline Canonista & 1 \\
\hline Total & $\mathbf{1 6}$ \\
\hline
\end{tabular}

Tabla 1. Cantidades de obras por temáticas según los catálogos coloniales ${ }^{22}$

21 El sello que Hernández y Carrasquilla (1977, Lámina LXX) creen de la Real Biblioteca Pública de Santafé de Bogotá, muy seguramente corresponde a la Biblioteca Pública de Bogotá, es decir al periodo republicano. Dice Eduardo Posada: «La Biblioteca se llamó después de la independencia Biblioteca pública, y se le puso a los libros un sello con este nombre en abreviatura, el cual se conserva en el Museo, junto con otro que parece decir Santafé, en forma de monograma» (Eduardo Posada, Narraciones: capítulos para la historia de Bogotá (Bogotá: Librería Americana, 1906), 305, probablemente se empezó a usar a partir del 25 de diciembre de 1823, fecha en que volvió a funcionar la Biblioteca, tras la muerte de Manuel del Socorro Rodríguez en 1819. Me inclino por la hipótesis de Posada ya que ninguno de los sellos tiene elementos monárquicos. Actualmente dichos sellos se conservan en el Museo Nacional de Colombia bajo los números de registro: 695 y 708.

22 Moralistas: RI 1, RI 2 y RI 35. Gramáticos: RI 3. Médicos: RI 13 y RI 15. Predicables: RI 17. Canonistas: RI 36 
En 1855, se utilizó un nuevo sello para la biblioteca y solo 11 títulos tienen este rótulo, como está pegado es muy posible que a los otros se le haya desprendido; dado que 16 incunables estaban en la BNC en 1823, 5 perdieron este rótulo.

En 1856, se imprimieron nuevos catálogos por idioma (español,francés, inglés y latín), y en ellos, las grandes temáticas cambiaron. Por ejemplo, el catálogo de las obras impresas en latín se dividió así: artes y oficios, ciencias eclesiásticas, ciencias físicas y matemáticas, ciencias naturales, filosofía, historia, literatura, medicina y, política y jurisprudencia; como se puede ver, las muchas temáticas religiosas que antes existían pasaron a llamarse ciencias eclesiásticas; y, la gramática se incluyó dentro de la literatura. Comparado con el Índice de 1823, que muestra una organización colonial de la biblioteca, la nueva catalogación cambia totalmente esta organización. El registro incluye el número del estante, el número de la obra, el autor, el título, el año de impresión y los tomos; aunque no siempre los datos están completos.

Nueve obras, de los incunables mencionados anteriormente, se encuentran referenciadas en el Catálogo de 1856. Aparecen por primera vez los incunables RI 39 y el RI $40^{23}$. No se encuentra el RI 03 que perteneció a los Jesuitas, a la Real Biblioteca de Santafé y a la Biblioteca Pública, varias pueden ser las explicaciones. Primero, porque no es sencillo identificar las obras dentro del catálogo, por ejemplo, de nuevo se le atribuyó a Hieronymus de Manfredis el RI 15pza. 1 siendo que su autor es Rhasis Mohammed; al igual que en el Índice de 1823 Guainerius Antonius es cambiado por "Suayneiro Antonius" (RI 13). Algunos libros no fueron incluidos en el catálogo, y aparecen vagamente descritos en dos hojas manuscritas al final del manuscrito 456, por ejemplo, hay uno que figura como "[autor anónimo]" y otro como "obra cristiana". Según las notas del mismo catálogo algunas

23 Biblioteca Nacional de Colombia, Catálogo de las obras en latín existentes en la Biblioteca Nacional (Bogotá: Imprenta del Estado, 1856), 12. Los incunables estaban incluidos en las obras en latín; estos son: RI 01, RI 02, RI 13, RI 15, RI 17, RI 35 y RI 36. 
obras fueron tomadas como duplicado pero en realidad eran diferentes ${ }^{24}$. Otro inconveniente tiene que ver con que "muchos están fuera de lugar; por ejemplo, entre ciencias eclesiásticas aparecen la obras poéticas de Petrarca y las médicas de Luis Mercado... No hay en la Biblioteca una sola obra cuyo título se haya copiado conforme a las reglas de la bibliografía..."25. Algunas de las obras referenciadas en el catálogo no fueron entregadas al bibliotecario José María Quijano Otero, hecho que este último aclaró en un ejemplar del mismo catálogo que contiene sus notas manuscritas ${ }^{26}$. Otra explicación a estas ausencias, es que la obra se encontrara fuera de la Biblioteca, dice el bibliotecario Tavera en su informe:

[...] parece que fue antigua la costumbre de prestar libros a domicilio, sin dejar siquiera nota de las personas que lo llevaban, y por este motivo hay muchas obras incompletas... Fue en 1873 que se abrió el primer libro o registro para anotar las obras u objetos que salen prestados del Instituto ${ }^{27}$.

Con la extinción de las comunidades religiosas, tras el decreto de 5 de noviembre de 1861 -dado por Tomás Cipriano de Mosquera-, entraron nuevas obras a la Biblioteca. El ingreso tuvo que darse luego de la emisión del decreto y antes de 1866, tiempo bajo el cual fue director Leopoldo Arias Vargas. Hasta 1868 solo habían entrado los libros de conventos extinguidos en Bogotá 28 , complementa Tavera: "han ingresado a la Biblioteca Nacional (...) los libros de los conventos de esta ciudad que fueron suprimidos, a saber: Dominicanos,

24 Biblioteca Nacional de Colombia, Catálogo de las obras, 46.

25 Miguel Antonio Caro, "Informe del Bibliotecario Nacional», en Memoria del secretario de instrucción pública dirigida al presidente de los Estados Unidos de Colombia para el Congreso en sus secciones de 1881 (Bogotá, Imprenta de Colunje y Vallarino, 1882), 124.

26 Hay varias existencias del Catálogo de 1856 en la BNC, para este estudio se utilizaron las siguientes: R 012.271 C334 y RM 456-pza. 4, este último contiene inscripciones manuscritas del bibliotecario José María Quijano Otero.

27 Gonzalo A. Tavera, «Bosquejo descriptivo de la Biblioteca Nacional de Colombia», Anales de la Universidad XIII, nº 91 (1879). El Decreto 634 de 1886, prohibió la salida de libros y documentos de la Biblioteca.

28 José María Quijano Otero, «Informe del Bibliotecario Nacional», en Memoria del Secretario de lo Interior y Relaciones Exteriores de los Estados Unidos de Colombia (Bogotá: Imprenta de la nación, 1868), 87-88. 
Franciscanos, Agustinos calzados y Agustinos descalzos" ${ }^{29}$. Diez incunables pertenecieron a los Franciscanos ${ }^{30}$, cinco más pertenecieron a los Agustinos ${ }^{31}$ y otros dos a los Dominicos ${ }^{32}$. Siete títulos pertenecieron a comunidades religiosas pero por la información del exlibris no se puede identificar a cuál ${ }^{33}$, en la mayoría de los casos se da el nombre del individuo y su posición en la institución pero no se escribió la comunidad a la que pertenecía.

El mismo Tavera dice: "[Entre] los libros pertenecientes a la Compañía de Jesús, hay pocas obras anteriores al primer advenimiento a este país de los padres de la Compañía, y solo en las librerías que pertenecieron a los conventos de Franciscanos, Dominicanos y Agustinos es que se encuentran algunos libros incunábulos"34; es la primera vez en la historia de la Biblioteca que se usa el término incunable. En ese momento, la BNC ya contaba con 16 títulos incunables, además de los 23 que habían entrado tras el decreto de extinción de las comunidades. Para 1879, el libro más antiguo identificado en la $\mathrm{BNC}$ era "Summa Ioannis Valensis de regimine vitae humane seu Margarita docto[rum] ad omne p[ro]positum: p[ro]ut patet in tabula" ${ }^{55}$, o sea el mismo que había identificado Manuel del Socorro Rodríguez, en 1795.

A comienzos de siglo, se "procedió a reunir en grupos especiales y situados convenientemente para su vigilancia y conservación, los libros raros, los incunables, los manuscritos,

29 Tavera, «Bosquejo descriptivo», 195.

30 Los que tienen exlibris de los Franciscanos son: RI 02, RI 4, RI 7, RI 8, RI 16 (dos títulos), RI 24 (3 títulos) y RI 25.

31 RI 5, RI 12, RI 27 (2 títulos) y RI 38.

32 RI 18 y RI 19.

33 RI 6, RI 14, RI 20, RI 23, RI 32 (dos títulos) RI 33.

34 Tavera, «Bosquejo descriptivo», 187.

35 Tavera, «Bosquejo descriptivo», 199. En la actualidad es el RI 1. Para los informes de los bibliotecarios durante el siglo XIX, el mismo Tavera dice "casi todos los años se han publicado las Memorias o Informes que el Director de la Biblioteca ha dirigido, anteriormente, al Señor Secretario de lo Interior y Relaciones Exteriores, y desde 1876 para adelante, al señor Rector de la Universidad” (Tavera, «Bosquejo descriptivo», 201). 
etc.”36. Seguramente este trabajo, sirvió para que Eduardo Posada, en 1906, estableciera el siguiente listado de incunables: "1. Valensis Ordinis Tratrum Minorum. De Regimine vitae humanae, Madrid, 1496. 2. Tabamalam Baptista, rosella casuns, 1499. 3. Manfredo Hieronymus, Medicina, 1500"37; como se puede ver hay algunas equivocaciones: se confunden los autores y las ciudades de impresión, no se entiende porque al número uno se lo ubica como impreso en Madrid, si Manuel del Socorro había establecido claramente su impresión en Venecia y en el número 3 hay dos obras, pero solo fue referenciada la primera. En total se desconocía la existencia de 36 incunables.

Según el informe del director de la Biblioteca, Gerardo Arrubla, presentado en 1912,

[...] la Biblioteca Nacional posee libros que por su antigüedad y rareza constituyen un verdadero tesoro, tales como los llamados incunables (...) [por esto, la Dirección] dispuso colocarlos en muebles apropiados, con sus vidrieras, tanto para que se conserven en el mejor estado posible, como para llamar la atención sobre ellos de las personas inteligentes ${ }^{38}$.

Continua Arrubla, "debido a la investigación reciente de que me ocupo, aparecieron seis incunables"39. Para 1913, Arrubla anota que la vitrina número 1 contiene 10 incunables universales, de los cuales el de Lectus Lucani no se encuentra en la colección de incunables hoy en día (para la época fue fechado en 1500 , pero sin duda es posterior $)^{40}$, y otros por estar en el mismo volumen no fueron contados, o sea que la Biblioteca creía tener 11 títulos. Del RI 25 dice "este ejemplar, es el más

36 Francisco J. Vergara, "Informe del director de la Biblioteca Nacional», en Informe que el ministro de Instrucción Pública presenta al Congreso de Colombia en sus secciones ordinarias de 1904 (Bogotá: Imprenta Nacional, 1904), 129.

37 Posada, Narraciones: capítulos, 310. En esta obra se utiliza por segunda vez el término incunable para referirse a los libros anteriores a 1501. RI 01, RI 02 y RI 15.

38 Gerardo Arrubla, «Informe el director de la Biblioteca Nacional», en Memoria del ministro de instrucción pública al Congreso de 1912 (Bogotá: Imprenta Nacional, 1912), 228-229.

39 Estos serían: RI 01, RI 02, RI 13, RI 15, RI 16, RI 17, RI 25 y RI 35.

40 Seguramente se refiere el al RV 83, Marci Annaei Lucani Pharsalia. 
antiguo de la biblioteca, fue hallado en estos días" y del RI 16 señala: "ambos libros están encuadernado en un volumen y se encontraron recientemente" 41 . Si se tienen en cuenta que 16 títulos pertenecieron a la Real Biblioteca de Santafé, y 23 entraron tras la supresión de comunidades religiosas, se puede concluir que en 1912 no se habían reconocido todos los incunables; no era que la BNC no los tuviera, sino que no se habían identificado.

En mayo de 1914, Arrubla decía que "tras una rebusca metodizada, se han podido separar quince incunables de clasificación mundial" ${ }^{42}$, cuando se creía que la Biblioteca solo poseía 3; no es fácil identificar los nuevos libros incluidos ya que solo cita el año de impresión, pero aproximadamente los títulos incunables, identificados en este momento debían ser 17, los once identificados en 1913, más el RI $14^{43}$, el RI 20 y el RI 36, la obra sin identificar con claridad es posiblemente el RI 24 , el cual cuenta con tres piezas, las cuales fueron impresas en 1500 y pertenecieron a la librería de San Francisco de Santa Fe.

Los incunables citados por Luis Enrique Forero, en 1926, son los mismos citados por Arrubla, incluso la de Lectus Lucani, el cual no es incunable ${ }^{44}$. Los registros del índice Forero cuentan con el autor, el título, la ciudad de impresión, el año y una nota sobre el contenido. Si se tienen en cuenta las obras empastadas en el mismo volumen, se saca el título

41 Gerardo Arrubla, «Del Director de la Biblioteca Nacional», en Informe del ministro de instrucción pública al Congreso de 1913 (Bogotá: Imprenta Nacional, 1913), 220.

42 Gerardo Arrubla, «Informe el director de la Biblioteca Nacional», en Memoria del ministro de Instrucción Pública al Congreso de 1914: documentos (Bogotá: Imprenta Nacional, 1914), 298-299.

43 En febrero de 1914 dice Arrubla sobre esta obra: «debido a las pacientes y desinteresadas investigaciones del erudito joven don Félix M. Guardado, se encontró otro libro incunable... el Repertorium de pravitate hereticorum et apostatarum... impreso en el año de 1494» (Gerardo Arrubla, citado por Guillermo Hernández de Alba y Juan Carrasquilla Botero, Historia de la Biblioteca Nacional (Bogotá: Instituto Caro y Cuervo, 305)).

44 Luis Enrique Forero, «Tesoro de la Biblioteca Nacional», Santafé y Bogotá VII, n 40 (1926), 162-166. 
repetido y la obra que no es incunable, la Biblioteca contaba con 18 títulos incunables, los cuales hoy en día aún están en la Biblioteca. Dicho índice no identificó el RI 3. El R1 36, "Repertorium de pravitate haereticorum. Ed: Miguel Albert", tienen una nota en la que se testifica que Forero reconoció el incunable el 11 de julio de 1922, si bien esta obra aparece en los índices de 1777, 1823 y 1856, esto confirma que los incunables no tuvieron un trato preferencial en el siglo XIX y fue solo hasta comienzos del XX que se les empezó a identificar y a dar un trato especial sobre el resto de la colección, estos pasaron de las vitrinas a "una caja metálica, adaptada al efecto en la sala de Dirección" "45. Igualmente se evidencia que los índices y catálogos antiguos no eran usados, así, si el catálogo de 1856 hubiese seguido en uso, Forero no se vería sorprendido por la aparición de un nuevo incunable, que existía en la colección desde el mismo momento en que inició la biblioteca.

El informe entregado por Daniel Samper Ortega, en 1931, es bastante sombrío: "se han encontrado, salvándolos de la humedad y de los ratones, los siguientes libros raros", y enumera 11 títulos incunables. Es un poco extraño que después del proceso que habían llevado a cabo Arrubla y Forero los incunables se encontraran en dichas condiciones, aunque Samper Ortega explica que no había suficiente dinero para el funcionamiento de la Biblioteca ${ }^{46}$.

Treinta y un obras tienen el sello de 1932, número que concuerda con el índice de incunables de $1934^{47}$, en el cual aparecen 19 volúmenes que contienen 31 títulos incunables. Incluye todas las obras del Inventario de 1767, todas las

45 Forero, «Tesoro de la», 163.

46 Daniel Samper, «Informe el director de la Biblioteca Nacional», en Memoria del ministro de Educación Nacional al Congreso de 1931, Tomo I, (Bogotá: Imprenta Nacional, 1931), 357-358. RI 3, RI 20, RI 25, RI 34 (dos títulos), RI 36 y RI 39. La obra Zachariae Lilii Vicetini orbis breviarium; fide compendio ordineq. captu, ac memoratu facillimum, posiblemente sea el RP 83, de 1525.

47 Biblioteca Nacional, «Nueva Serie de incunables», Senderos II, nº 9, (1934): 180184. El informe de 1935 seguramente tiene un error ya que dice: «en líneas generales bastará decir que poseemos 33 volúmenes con 86 obras en total, de incunables anteriores a 1500» (Biblioteca Nacional de Colombia, "Informe del director de la Biblioteca Nacional» Senderos II, n 16 y 17 (1935): 629). 
que pertenecieron a los Jesuitas, las que entraron a la Real Biblioteca de Santafé, las que aparecen en el Índice de 1823 y las identificadas por Luis Enrique Forero. Si se tienen en cuenta las obras empastadas en el mismo volumen, se saca el título repetido y la obra que no es incunable, la Biblioteca contaba con 26 títulos incunables, los cuales hoy en día aún están en la Biblioteca.

La revista Senderos, órgano de difusión de la BNC, publicó 2 listados de incunables, uno preliminar en junio de 1934, y uno completo en octubre del mismo año, este último puede considerarse como el primer índice de incunables y seguramente fue el prototipo del primer catálogo; los registros cuentan con el autor, el título y el año de publicación. En total reporta apenas 19 títulos, aunque el informe del director de 1934 hablaba de 86 incunables $^{48}$. Hacia inicios de 1934 las obras fueron ubicadas en la oficina del director. En 1935,

[...] estos libros fueron estudiados uno a uno, en orden riguroso, sin atender a sus dimensiones ni a otra consideración de método... [Luego]... se procedió a arreglarlos según el orden en que por sus tamaños habían quedado colocados en los anaqueles, y realizada esta operación se le dejó a cada uno en el lomo el nombre del autor, título de la obra, ciudad y año de impresión ${ }^{49}$.

En 1940, se mecanografió el primer y único catálogo en papel que se ha hecho sobre los incunables de la $\mathrm{BNC}^{50}$, lo elaboró el funcionario Juan Bueno Medina. De los seis tomos que tiene la obra, únicamente el primero es dedicado a los incunables. Divide los libros por países -en el siguiente orden: Alemania, Italia, Suiza, Francia y España-, luego por ciudades de impresión -en el siguiente orden: Estrasburgo,

48 Luis López de Mesa, Gestión administrativa y perspectiva del Ministerio de Educación - 1935, (Bogotá: Imprenta Nacional, 1935), 176.

49 Biblioteca Nacional de Colombia, «Informe del director» 1935, 628.

50 Juan B. Bueno, Catálogo de Incunables de la Biblioteca Nacional de Bogotá (Bogotá, Biblioteca Nacional, 1940). Se pensó en que esta obra sería impresa, pero dado que la Imprenta Nacional no contaba con «los tipos especiales requeridos para un libro de esta naturaleza", nunca fue realizado este proyecto (Ministerio de Educación Nacional, La obra educativa del gobierno en 1940 (Bogotá: Imprenta Nacional, 1940), $54)$. 
Núremberg, Venecia, Brescia, Basilea, París, Lyon, Valencia, Sevilla, Burgos, Monserrate y Zaragoza- y los organiza cronológicamente dentro de cada ciudad, asignándole un número consecutivo a cada incunable; de esta forma el libro más antiguo de Estrasburgo tiene el primer número y el incunable más reciente de Zaragoza tiene el último número. Como el catálogo tomó en cuenta los libros impresos hasta 1530, la numeración llega hasta 267.

Bueno Medina incluye índices de ciudades, impresores y editores, y autores. Los registros cuentan con una corta biografía del autor, el título de la obra, la transcripción del colofón, el nombre del impresor; una descripción de las letras, la cantidad de líneas, las abreviaturas, las columnas, la paginación, el tamaño y la encuadernación. El trabajo tiene algunas inconsistencias, confunde el nombre de los autores, cambia títulos de capítulos por títulos de la obra, intercambia las ciudades, desacierta en las fechas de impresión. En total, 48 incunables aparecen en el Catálogo; únicamente faltan el RI 26: Sermones de laudibus Sanctor, et dominicales per totum annuz cu aliqbus tractatib' utilimis pro predicadi officio p clarissimi sacre theologie doctoris illuinati magistri Fracisci de Mayrois y el RI 37: Summa contra gentiles, sive De veritate Catholicae fidei, ausencias que serán explicadas más adelante; estas dos obras tampoco aparecen en los informes de Arrubla, Forero y Samper Ortega.

Las mismas 48 obras del Catálogo de Bueno Medina tienen el sello de 1948. Carecen de este las dos obras mencionadas en el párrafo anterior, las cuales tampoco fueron tenidas en cuenta en el inventario levantado por la Contraloría entre julio de 1948 y agosto de 1949, ya que carecen de la firma de Octavio Quiñones Pardo, el visitador fiscal ${ }^{51}$. Mientras se estaba desarrollando dicho inventario, se detectó la pérdida de algunos libros, por tanto se construyó la sala de seguridad

51 La Contraloría se hizo presente en la BNC debido al llamado que hizo el director Eduardo Carranza (Fernando Rivas Sacconi, «Acta relativa a los incunables universales o clásicos de la Biblioteca Nacional», (Bogotá, 21 de febrero de 1957), Archivo BNC). 
como una forma de mejorar la custodia de los incunables, el 2 de mayo de 1949 las obras pasaron de la oficina de dirección a dicho espacio ${ }^{52}$. Actualmente no están en la $\mathrm{BNC}$ los números 33,35 y 36 , seguramente estos números estaban asignados a los incunables perdidos. Así mismo, el RI 26 tiene escrito el número "doscientos sesenta y ocho" y el RI 37 tiene escrito el número "doscientos sesenta y nueve"; o sea que estos libros fueron ingresados en esta clasificación tardíamente.

En 1957, escribía el director sobre los incunables: "en la actual colocación de los libros por catalogación decimal no se han tenido en cuenta para nada el orden de la numeración hecha por Quiñones Pardo" ${ }^{33}$.

En la Exposición de libros incunables, raros y curiosos, de $1962^{54}$, aparecen 40 volúmenes. En este pequeño catálogo figura el RI 37, o sea que el incunable más antiguo fue detectado en la Biblioteca entre 1948 y 1962 . El RI 26 no aparece en este catálogo, ni en los anteriores, tampoco el RI 18 aunque este último sí aparece en otros índices preliminares. Con estas pistas se buscó información comprendida en este periodo, y se encontró en el Boletín Cultural de la BNC un pequeño artículo que no deja ninguna duda sobre el ingreso del RI 26 y del RI 37:

Al tesoro de incunables de la Biblioteca Nacional han ingresado recientemente dos valiosos volúmenes, catalogados como incunables (...) Los títulos de las obras son los siguientes: $1^{\circ}$. "Sermonis de Sanctis" y otros tratados de Franciscus de Maioranis, edición publicada en Venecia el año de 1493; $2^{\circ}$. "Summa contra gentiles sive de veritate catholicae fidei" de Tomás de Aquino, esta obra salió de la imprenta de Nicolaus Jenson en Venecia, el año de $1480^{55}$.

52 Uno de los sospechosos era el mismo Juan Bueno Medina, quien elaboró el único catálogo de incunables que se ha hecho en la Biblioteca. Octavio Quiñones, «Acta de entrega de los libros incunables de la Biblioteca Nacional», (Bogotá, 22 de agosto de 1949), Archivo BNC.

53 Rivas Sacconi, "Acta relativa», 3.

54 Biblioteca Nacional de Colombia, Exposición de libros incunables raros y curiosos (Bogotá: Biblioteca Nacional, 1963).

55 Biblioteca Nacional de Colombia, «Nuevos incunables adquiere la biblioteca», Boletín Cultural 27, (28 de agosto 1953) s.p. 
Dice Delia Palomino en su informe, de 1984, que estos dos libros fueron adquiridos mediante compra ${ }^{56}$.

La siguiente tabla resume los años en que ingresaron los incunables y su procedencia.

\begin{tabular}{|l|c|c|}
\hline \multicolumn{1}{|c|}{ Procedencia } & Periodo de Ingreso & Cantidad \\
\hline Jesuitas Bogotá & 1767 & 10 \\
\hline Jesuitas Otras & $1767-1776$ & 2 \\
\hline Desconocida & $1777-1823$ & 4 \\
\hline Desconocida & $1824-1856$ & 2 \\
\hline Franciscanos & 1861 & 9 \\
\hline Agustinos & 1861 & 5 \\
\hline Dominicos & 1861 & 2 \\
\hline Comunidades sin identificar & 1861 & 9 \\
\hline Desconocida & $1932-1948$ & 5 \\
\hline Desconocida & 1953 & 2 \\
\hline
\end{tabular}

Tabla 2. Procedencia de los incunables y año de ingreso a la BNC.

Para resumir el asunto de la organización de los incunables, se tiene que en los índices de 1767, 1790 y 1823 estaban difuminados dentro de colección y ubicados dentro de cada una de las temáticas; esto obedeciendo a las normas de la época y a un momento en que la cantidad de libros era limitada. En 1856, la organización cambió, estos libros fueron situados con el resto de obras en latín y ubicados en las grandes temáticas de dicho catálogo, situación entendible dado el descenso en el uso del latín, la solidez del francés y el fortalecimiento del inglés. En las primeras dos décadas del siglo XX las obras fueron separadas de la colección para ejercer una más efectiva vigilancia y ser expuestas al público en vitrinas, si bien luego fueron pasadas a cajas metálicas. A mediados de los años treinta pasaron a la oficina de dirección, se catalogaron individualmente y se organizaron por tamaño. En 1940, se hizo una nueva organización por ciudades de impresión, iniciando en Estrasburgo y terminando en Zaragoza, a cada título se le asignó un número, iniciando en 1 y terminando en 267, aunque con la inclusión de dos incunables

56 Delia Palomino, "Informe sobre el primer fondo bibliográfico de la sala de seguridad: los incunables» (Bogotá, 21 de agosto de 1984), Archivo de la BNC, Caja 3, carpeta 28,8 . 
en 1953, se llegó a 269. En los años cincuenta, se mantuvieron juntos pero su clasificación cambió al sistema Dewey. En 1998, los incunables se separaron del resto de libros antiguos y, se les asignó una nueva organización y signatura: las letras RI seguidas de un consecutivo numerario.

\section{Los extraviados}

Es posible que algunos de los registros con fecha anterior a 1500 y que aparece en los índices y catálogos sean de ejemplares ficticios, cuya fecha de impresión es posterior y por tanto dicha edición incunable no existe.

En el Índice general de libros que tiene esta Real Biblioteca pública de la ciudad de Santafé existe el siguiente registro: "Discípulo. Sermones. 1 tomo a vecerra, en [Lyon], en 1500, no $1 " 57$, dado que no está especificado el autor es difícil la identificación exacta de la edición; si bien en el ISTC existen tres obras con estas características; también podría ser una de la obras de Jacobus de Vorágine, pero estás pertenecieron a los Franciscanos y no tienen sello de la Biblioteca Pública, tampoco aparece en el índice de 1856.

Según el Catálogo de 1856 las obras que no se encuentran en la actualidad en la BNC son:

1. Turrecremata, expositio in psalterium, $1500^{58}$. En el ISTC existen dos ediciones de Expositio super toto psalterio, una de 1502 (Venecia) y otra de después de 1500 (Paris), de la primera existe una copia en la BNC, muy seguramente sea la que se tenía como incunable.

2. Lacanus, Carmina, 1500. Muy posiblemente esta es la misma obra que se identifica como hurtada, entre 1942 y 1948, lo curioso es que ambos registros caen en el mismo error: fecharla en 1500, cuando no existe una obra con estas características, o sea es una obra ficticia ${ }^{59}$.

57 Biblioteca Nacional de Colombia, Índice general de, f. 103 recto § 5.

58 Esta obra aparece en el Inventario de la Biblioteca Común del Colegio Máximo, con el siguiente registro: Joannes Turrecremata In Psalmos. 1 tomo, 4a, pergamino, no 5 (Verasttegui y Moreno. Inventario de la Biblioteca Común, f. 12 § 21).

59 Biblioteca Nacional de Colombia, Catálogo de las obras, 57 y 89. 
Como se ha visto, pueden ser varias las explicaciones sobre la pérdida de libros en la BNC. Una nota en un catálogo puede explicar tal situación, al referirse a 6 de estas obras dice: "completamente dañadas por una gotera, inútiles"60.

\section{El director, Enrique Álvarez Bonilla afirmaba:}

[...] con frecuencia sucede que los particulares proponen canjes de obras modernas por ejemplares de antiguas de que haya más de una. Como no simpatizo con esta especie de cambios, no he celebrado arriba de dos, y eso con expresa aprobación de ese Ministerio y con evidentes ventajas, a mi juicio, para la Biblioteca. Obras hay de antigua edición que hoy tienen en Europa un alto precio, sin más que por su carácter de antigüedad (...) Existe en esta Biblioteca una obra antigua que, al parecer, vale unos 40 centavos, y sin embargo puede estimarse en unos $\$ 200^{61}$.

Por otro lado, el 10 de abril de 1894, se hizo una transferencia de 11.477 libros, que trataban sobre idiomas muertos y asuntos eclesiásticos, al Seminario Conciliar, este pudo ser otro de los caminos que tomaron los libros faltantes en la $\mathrm{BNC}^{62}$.

\section{Decía Gerardo Arrubla en mayo de 1915:}

[...] en el mes de noviembre del año pasado esta dirección descubrió que un asiduo lector de la biblioteca (...) había sustraído libros que pertenecían a este establecimiento. Procediendo con actividad, se recuperaron todos los libros perdidos; muchos de ellos pudo comprobarse habían desaparecido de los anaqueles hacía más de ocho años ${ }^{63}$.

60 Biblioteca Nacional de Colombia, Catálogo de las obras, 4.

61 Enrique Álvarez, «Informe del director de la Biblioteca Nacional», en Informe que el ministro de instrucción pública presenta al Congreso de Colombia en sus secciones ordinarias de 1890, Tomo Segundo (Bogotá: Imprenta de La Luz, 1890), 79-80.

62 Enrique Álvarez, "Informe del Director de la Biblioteca Nacional», en Informe que el ministro de instrucción pública presenta al Congreso de Colombia en sus sesiones ordinarias de 1894 (Bogotá: Imprenta de la Luz, 1894), 154.

63 Gerardo Arrubla, «Informe del director de la Biblioteca Nacional», en Memoria del ministro de instrucción pública al Congreso de 1915 (Bogotá: Imprenta Nacional, 1915), 348). 
Según el oficial mayor de la Biblioteca, Luis Enrique Forero, en 1926, de la obra "Repertorium de pravitate haereticorum" existían 2 copias $^{64}$, pero en estos momentos la Biblioteca solo cuenta con una.

Revisando el listado de incunables de junio ${ }^{65}$ y octubre de $1934^{66}$, el Catálogo de Bueno Medina ${ }^{67}$ y teniendo en cuenta el archivo de la $\mathrm{BNC}^{68}$, otros incunables sustraídos son los enunciados a continuación ${ }^{69}$. Dado que las obras tres y cuatro del listado, se encuentran en el Catálogo de la exposición que hizo la Biblioteca Nacional en $1942^{70}$, el hurto de estas obras se dio entre 1942 y 1948.

\begin{tabular}{|l|}
\hline \multicolumn{1}{|c|}{ Título } \\
\hline Deza Didacus. In defensiones Sancti Thomae. Sevilla, 14091. 96 folios. \\
\hline Reginaldeti Petrus. Speculum finalis retributionis. Lyon, 1494. 65 folios. \\
\hline $\begin{array}{l}\text { Aquinas Thomas. Comentaria in Epistolas Pauli. Basilea, Michael Furter, } 16 \text { de } \\
\text { octubre de 1495. 290 folios. }\end{array}$ \\
\hline $\begin{array}{l}\text { Gordonio Bernardo. Lilio de Medicina. Sevilla, Meynardo Ungt y Stanislao Polono, } \\
18 \text { de abril de 1495. 224 folios. }\end{array}$ \\
\hline Paraldus Guilhelmus. Summarium summae virtutum et vitiorum. Basilea: 1497. \\
324 folios. \\
\hline Aquinas Thomas. Secundus liber sententiarum. Venecia, 1498. 156 folios. \\
\hline Sandei Felini. Comentaria. Lyon, 1482, 243 fls. $^{71}$ \\
\hline M. Annaeus Lucanus. Bellum Civile Pharsalicum. Lugduni, Antonius du Ry, 150072 \\
\hline
\end{tabular}

Tabla 3. Incunables posiblemente perdidos.

64 Forero, «Tesoro de la», 162-166.

65 Biblioteca Nacional de Colombia, «Incunables», Senderos I, n 5, (1934): 263264).

66 Biblioteca Nacional de Colombia, «Nueva Serie de».

67 Bueno Medina, Catálogo de Incunables de.

68 Palomino, «Informe sobre el primer», 1-9.

69 Otro hurto había tenido lugar en la BNC entre 1934 y 1937, para más información ver: Aníbal Currea, El robo Ortíz Vargas en la Biblioteca Nacional (Bogotá: Editorial $\mathrm{ABC}, 1937)$.

70 Biblioteca Nacional de Colombia, Exposición libro: Biblioteca Nacional, 26 de julio a 26 de agosto de 1942 (Bogotá: Biblioteca Nacional, 1942).

71 No está en el ISTC, probablemente sea una obra ficticia, ya que no existe nada parecido. Esta obra aparece como adquirida en el Informe, pero actualmente no está en la BNC (Palomino, «Informe sobre el primer fondo», 6). La misma obra apareció en el listado de Ungar (Hans Ungar, «Imprenta e Incunables: los Incunables de la Biblioteca Nacional», Gaceta XI, n 19 (1978): 28.

72 No está en el ISTC, muy seguramente es la siguiente obra: Lucani Pharsalia cum annotationibus Sulpitii et Chappusoti. Lugduni: Antonium du Ry impensis Symonis 


\section{Conclusiones}

Son pocos los trabajos sobre incunables que se han hecho en Colombia, la mayoría se han encargado de la catalogación de los libros, pero no de explicar cómo se formaron las colecciones, cómo han sido tratados estos en las instituciones, cuáles han sido sus usos y cuál es su valor patrimonial. La Universidad de los Andes, del Rosario, la Javeriana y la Biblioteca Luis Ángel Arango, son las instituciones que han hecho trabajos sobre incunables en Bogotá. Los trabajos de Cali y Cúcuta son los únicos hechos fuera de la capital. No se sabe con certeza sobre la existencia de incunables en otros lugares del país, como las ciudades coloniales importantes o los centros urbanos más sobresalientes en la actualidad ${ }^{73}$. También se desconocen los libros que tienen el clero secular y el regular, o aquellos que se encuentran en poder de los coleccionistas privados. En este aspecto es importante resaltar que no existe una política que promueva la catalogación y difusión del libro antiguo, como un elemento del patrimonio cultural. La BNC ha pensado elaborar un censo nacional de incunables, en un comienzo para tener la ubicación de los mismos y tal vez luego, para hacer una propuesta de conocimiento (partes, usos, circulación, pertenencia, etc.) y difusión del libro antiguo.

Los incunables de la BNC no tienen una única procedencia, si bien en su mayoría provienen de comunidades religiosas (Jesuitas, Franciscanos, Agustinos y Dominicos). Su ingreso a la Biblioteca se debe a situaciones que ocurrieron en diferentes momentos históricos, por eso algunos entraron en el siglo XVIII, otros en el XIX y unos pocos en el XX, como la obra de 1480, que es la más antigua que posee la BNC.

\footnotetext{
Vincentii, 1523. Posiblemente sea la misma obra referenciada en Forero, «Tesoro de la», 89 .

73 Alfonso Rubio asegura que la Biblioteca Mario Carvajal de la Universidad del Valle tiene un incunable (Rationale Divinorum officiorum, 1500) y, aunque sin fecha de impresión, sospecha de que el Sanctus Thomas de Aquino super quartum librum magistri senteniar (1497?) es otro incunable (Alfonso Rubio, Libros antiguos en la Universidad del Valle (Cali: Programa Editorial Universidad del Valle, 2014), 13-14). En 2015, la EAFIT compró el libro De arte amandi y De remedio amoris (Venecia: Johannes Tacuinus, de Tridino, 1494).
} 
Aunque se debe dejar claro que la custodia, catalogación y clasificación por parte de la BNC ha presentado diferentes problemas; en algunos casos por desconocimiento de los temas, en otros por falta de cumplimiento de las normas. Fue a inicios del siglo XX cuando los incunables empezaron a tener un trato especial, seguramente por los importantes trabajos que surgieron en Europa y por el surgimiento de los estudios alrededor del libro. Y fue hasta la década de los treinta cuando se hizo una esmerada catalogación, después de que la Biblioteca pasó a su nuevo edificio (1938) e inició modernos procesos de catalogación ${ }^{74}$. Así, se les separó de los fondos a los que pertenecían, se juntaron en una sola colección y se limitó su acceso, únicamente a los investigadores. A finales del XVIII y comienzos del XIX apenas habían sido identificados y eran tratados como los demás libros; el resto del siglo XIX estuvo marcado por su ausencia de la colección. De esta forma, nos damos cuenta que cada época tiene una relación diferente con el libro, y cada periodo de tiempo lo valora y lo trata de forma diferente.

Internet y la digitalización de las obras, por un lado, han ayudado a mejorar el conocimiento que tenemos sobre los incunables, y por otro, a facilitar el acceso al libro antiguo; o sea el patrimonio bibliográfico está disponible para más personas en más lugares del territorio.

\begin{tabular}{|l|l|}
\hline Signatura & \multicolumn{1}{|c|}{ Título } \\
\hline RI 01 & $\begin{array}{l}\text { Summa Ioannis Valensis de regimine vitae humane seu Margarita } \\
\text { docto[rum] ad omne p[ro]positum: p[ro]ut patet in tabula }\end{array}$ \\
\hline RI 02 & Summa casuum conscientiae \\
\hline $\begin{array}{l}\text { RI 03, } \\
\text { pza. 1 }\end{array}$ & Aelii Antonii Nebrissensis gramatici introductionum latinarum \\
\hline $\begin{array}{l}\text { RI 03, } \\
\text { pza. 2 }\end{array}$ & Elegantie Augustini dati pro iuvenibus perutiles \\
\hline
\end{tabular}

74 En 1921, se utilizó por vez primera el sistema de Clasificación Decimal Dewey por Luis Enrique Forero, pero se dejó de usar, hasta que en 1936, bajo la dirección de Daniel Samper, Miss Janeiro Brooks reinició la tarea de arreglar decimalmente los libros (Biblioteca Nacional de Colombia, Sistema decimal Dewey para organización bibliotecaria. (Bogotá: Prensas de la Biblioteca Nacional, 1944), 5-6). Forero llamó a esto la reorganización de "la Biblioteca Nacional sobre bases científicas de conservación y funcionamiento» (Forero, «Tesoro de la», 162). 


\begin{tabular}{|c|c|}
\hline Signatura & Título \\
\hline $\begin{array}{l}\text { RI 03, } \\
\text { pza. } 3\end{array}$ & Opusculo epistolarum familiarum \& artis \\
\hline $\begin{array}{l}\text { RI 03, } \\
\text { pza. } 4\end{array}$ & Elegancias romançadas de lebrixa \\
\hline $\begin{array}{l}\text { RI 03, } \\
\text { pza. } 5\end{array}$ & In vafre dicta philosophorum Antonii Nebrisseñsis. glossemata. \\
\hline $\begin{array}{l}\text { RI } 03, \\
\text { pza. } 6\end{array}$ & $\begin{array}{l}\text { Alconiae probae foemine eruditissimae ad Adelphû senatorem } \\
\text { coniûgem dulcissimû ex Virgilii operibus centones veteris ac Novi } \\
\text { Testameti }\end{array}$ \\
\hline $\begin{array}{l}\text { RI 03, } \\
\text { pza. } 7\end{array}$ & $\begin{array}{l}\text { Leonardi Aretini Viri laudatissimi ad Colutium Oratoren in Magni } \\
\text { Basilii libellum praefatio }\end{array}$ \\
\hline $\begin{array}{l}\text { RI 03, } \\
\text { pza. } 8\end{array}$ & No incunable \\
\hline RI 04 & Santorum legendis \\
\hline RI 05 & Preclarissima Opuscula \\
\hline RI 06 & Caecilii Cypriani Opera \\
\hline RI 07 & Operum. Gerson, Joannes \\
\hline RI 08 & Operum. Gerson, Joannes \\
\hline RI 09 & No Incunable \\
\hline RI 10 & $\begin{array}{l}\text { [Quaestiones super quator libros sententiarum Petri Lombardi cum } \\
\text { textu ejusdem. Secunda et quarta pars] V. II }\end{array}$ \\
\hline RI 11 & $\begin{array}{l}\text { Quaestiones super quator libros sententiarum Petri Lombardi cum } \\
\text { textu ejusdem. Secunda et quarta pars] V. IV }\end{array}$ \\
\hline RI 12 & Concordantiae bibliorum \\
\hline RI 13 & Opera medica \\
\hline RI 14 & $\begin{array}{l}\text { Homiliarius doctorum de tempore et de sanctis a Paulo Diacono } \\
\text { collectus }\end{array}$ \\
\hline $\begin{array}{l}\text { RI } 15, \\
\text { pza. } 1\end{array}$ & $\begin{array}{l}\text { Liber ad Almansorem sive Tractatus medicinae I-X. Add: Liber } \\
\text { divisionum; De aegritudinibus juncturarum; De aegritudinibus } \\
\text { puerorum; De secretis sive aphorismi; Antidotarium; De } \\
\text { praeservatione ab aegritudine lapidis; Introductorium medicinae; De } \\
\text { sectionibus et ventosis; Synonyma; De animalibus. Tabula de herbis } \\
\text { medicis. Hieronymus de Manfredis: Centiloquium de medicis }\end{array}$ \\
\hline $\begin{array}{l}\text { RI } 15, \\
\text { pza. } 2\end{array}$ & $\begin{array}{l}\text { Aphorismi secundum doctrinam Galeni. Add: Johannes Damascenus } \\
\text { [Mesue?]: Aphorismi. Hippocrates: Secreta; Prognosticatio secundum } \\
\text { lunam; Capsula eburnea; De humana natura; De aere et aqua et } \\
\text { regionibus; De pharmaciis; De insomniis. Avenzohar: De curatione } \\
\text { lapidis }\end{array}$ \\
\hline $\begin{array}{l}\text { RI } 16, \\
\text { pza. } 1\end{array}$ & Liber meditationu vite Domini Nostri Iesu-Christi \\
\hline $\begin{array}{l}\text { RI 16, } \\
\text { pza. } 2\end{array}$ & Tractus de spiritu albinus ascensionibis \\
\hline $\begin{array}{l}\text { RI } 17, \\
\text { pza. } 1\end{array}$ & $\begin{array}{l}\text { Sermones aurei et pulcherrimi variis scripturarum doctrinis referti } \\
\text { de tempore p. totum anni }\end{array}$ \\
\hline $\begin{array}{l}\text { RI } 17, \\
\text { pza. } 2\end{array}$ & $\begin{array}{l}\text { Sermones pulcherrimi variis scripturarum doctrinis referti de sanctis } \\
\text { per anni totius circulum concurrentibus editi a venerabili viro sacre } \\
\text { theologie professore Jacobo de Voragine ordinis }\end{array}$ \\
\hline
\end{tabular}




\begin{tabular}{|c|c|}
\hline Signatura & Título \\
\hline RI 18 & \begin{tabular}{|l}
$\begin{array}{l}\text { Sermones magistri, Sermones quadragesimales, Sermones de } \\
\text { passione, Sermones de Sactis }\end{array}$ \\
\end{tabular} \\
\hline RI 19 & Sermones dormi secure dominicales Sermones de sancti dormi secure \\
\hline RI 20 & Sermones Roberti de Sanctis \\
\hline RI 21 & No Incunable \\
\hline RI 22 & Corona aurea coruscantibus gemmis \\
\hline RI 23 & $\begin{array}{l}\text { Preceptorium divine legis venerabilis fratris Johanis Nider de Ordini } \\
\text { Predicatorum }\end{array}$ \\
\hline $\begin{array}{l}\text { RI } 24, \\
\text { pza. } 1\end{array}$ & $\begin{array}{l}\text { Expositio magistri Petri Tatareti super summulas Petry hispani cum } \\
\text { additionibus in locis. P priis }\end{array}$ \\
\hline $\begin{array}{l}\text { RI } 24, \\
\text { pza. } 2\end{array}$ & Expositio magistri Petri Tatareti super textu logices Aristotelis \\
\hline $\begin{array}{l}\text { RI } 24, \\
\text { pza. } 3\end{array}$ & $\begin{array}{l}\text { Clarissima singularisque totiua philosophie necnon metaphisice } \\
\text { Aristotelis. magistri Petri Tatareti expositio }\end{array}$ \\
\hline RI 25 & Quadragesimale doctoris illuminati Francisci Mayronis \\
\hline RI 26 & $\begin{array}{l}\text { Sermones de laudibus Sanctor, et dominicales per totum annuz cu } \\
\text { aliqbus tractatib' utilimis pro predicadi officio p clarissimi sacre } \\
\text { theologie doctoris illuinati magistri Fracisci de Mayrois }\end{array}$ \\
\hline $\begin{array}{l}\text { RI } 27, \\
\text { pza. } 1\end{array}$ & Aurelii Augustini opuscula plurima: quedam non plus impressa \\
\hline $\begin{array}{l}\text { RI } 27, \\
\text { pza. } 2\end{array}$ & Plurima Opuschula sanctiaugustini \\
\hline RI 28 & $\begin{array}{l}\text { Liber Floreti in quo flores oïm virtutu. et detestationes vitior. metrite } \\
\text { continetur una cum commento }\end{array}$ \\
\hline RI 29 & No Incunable \\
\hline RI 30 & No Incunable \\
\hline RI 31 & Opera. Ed: Johann Amerbach, Johannes (Heynlin) de Lapide \\
\hline $\begin{array}{l}\text { RI } 32, \\
\text { pza. } 1\end{array}$ & In Somnium Scipionis expositio. Saturnalia \\
\hline $\begin{array}{l}\text { RI } 32, \\
\text { pza. } 2\end{array}$ & $\begin{array}{l}\text { De natura deorum. Add: De divinatione. De legibus, Academica. De } \\
\text { finibus bonorum et malorum. De fato, Timaeus, Somnium Scipionis. } \\
\text { Quintus Tullius Cicero: Commentariolum petitionis }\end{array}$ \\
\hline RI 33 & $\begin{array}{l}\text { De evangelica praeparatione. Tr: Georgius Trapezuntius. Ed: } \\
\text { Hieronymus Bononius }\end{array}$ \\
\hline RI 34, pza. 1 & $\begin{array}{l}\text { Sphaera mundi. Comm: Cecco d'Ascoli, Franciscus Capuanus, } \\
\text { Jacobus Faber Stapulensis. Add: Georgius Purbachius: Theoricae } \\
\text { novae planetarum. Comm: Franciscus Capuanus. }\end{array}$ \\
\hline $\begin{array}{l}\text { RI } 34, \\
\text { pza. } 2\end{array}$ & $\begin{array}{l}\text { Opus (Ed: doctrinae Scoticae in Thomistas Joannes Antonius } \\
\text { Patavinus) }\end{array}$ \\
\hline RI 35 & Summa que destructorium viciorum apellat \\
\hline RI 36 & Repertorium de pravitate haereticorum. Ed: Miguel Albert \\
\hline RI 37 & $\begin{array}{l}\text { Summa contra gentiles, sive De veritate Catholicae fidei. Ed: Petrus } \\
\text { Cantianus }\end{array}$ \\
\hline RI 38 & $\begin{array}{l}\text { Biblia latina (cum postillis Nicolai de Lyra et expositionibus Guillelmi } \\
\text { Britonis in omnes prologos S. Hieronymi et additionibus Pauli } \\
\text { Burgensis replicisque Matthiae Doering). Ed: Paulus a Mercatello. } \\
\text { With additions by Franciscus Moneliensis. Add: Nicolaus de Lyra, } \\
\text { Contra perfidiam Judaeorum }\end{array}$ \\
\hline
\end{tabular}




\begin{tabular}{|l|l|}
\hline Signatura & \multicolumn{1}{|c|}{ Título } \\
\hline RI 39 & Repertorium morale (Ed: Johannes Beckenhaub). V. 1 \\
\hline RI 40 & Repertorium morale (Ed: Johannes Beckenhaub). V.2 \\
\hline
\end{tabular}

Tabla 4. Relación de textos incunables BNC.

\section{Fuentes documentales}

Álvarez, Enrique. «Informe del director de la Biblioteca Nacional». En Informe que el ministro de instrucción pública presenta al Congreso de Colombia en sus secciones ordinarias de 1890. Tomo Segundo. Bogotá: Imprenta de La Luz, 1890.

. «Informe del Director de la Biblioteca Nacional».

En Informe que el ministro de instrucción pública presenta al Congreso de Colombia en sus sesiones ordinarias de 1894. Bogotá: Imprenta de la Luz, 1894.

Arrubla, Gerardo. «Del Director de la Biblioteca Nacional». En Informe del ministro de instrucción pública al Congreso de 1913. Bogotá: Imprenta Nacional, 1913.

. «Informe del director de la Biblioteca Nacional». En Ministerio de Instrucción Pública, Memoria del ministro de instrucción pública al Congreso de 1912. Bogotá: Imprenta Nacional, 1912.

«Informe el director de la Biblioteca Nacional».

En Memoria del ministro de instrucción pública al Congreso de 1914: documentos. Bogotá: Imprenta Nacional, 1914.

. «Informe del director de la Biblioteca Nacional».

En Memoria del ministro de instrucción pública al Congreso de 1915. Bogotá: Imprenta Nacional, 1915.

Biblioteca Nacional de Colombia. Catálogo de las obras en latín existentes en la Biblioteca Nacional. Bogotá: Imprenta del Estado, 1856.

Colecciones de la Biblioteca Nacional: Tipos y organización física. Versión 9. Bogotá: Biblioteca Nacional de Colombia, noviembre 2001. 
Exposición de libros incunables raros y curiosos.

Bogotá: Biblioteca Nacional, 1963.

Exposición libro: Biblioteca Nacional, 26 de julio a 26 de agosto de 1942. Bogotá: Biblioteca Nacional, 1942.

Índice general de libros que tiene esta Real Biblioteca pública de la ciudad de Santafé, Bogotá, [1790]?.

Índice alfabético de los libros de la Biblioteca pública de la ciudad de Santa Fe de Bogotá, Bogotá, 1823.

. «Informe del director de la Biblioteca Nacional». Senderos II, nº 16 y 17 (1935): 628-53.

"Nuevos incunables adquiere la biblioteca». Boletín Cultural 27 (1953) s.p.

- Sistema decimal Dewey para organización bibliotecaria. Bogotá: Prensas de la Biblioteca Nacional, 1944.

Bueno, Juan. B. Catálogo de Incunables de la Biblioteca Nacional de Bogotá. Bogotá: Biblioteca Nacional, 1940.

Caro, Miguel Antonio. |Informe del Bibliotecario Nacional». En Memoria del secretario de instrucción pública dirigida al presidente de los Estados Unidos de Colombia para el Congreso en sus secciones de 1881. Bogotá: Imprenta de Colunje y Vallarino, 1882.

Currea, Aníbal. El robo Ortíz Vargas en la Biblioteca Nacional. Bogotá: Editorial ABC, 1937.

Forero, Luis Enrique. «Tesoro de la Biblioteca Nacional». Santafé y Bogotá 4, nº 40 (1926): 162-166.

López de Mesa, Luis. Gestión administrativa y perspectiva del Ministerio de Educación-1935. Bogotá: Imprenta Nacional, 1935.

Ministerio de Educación Nacional. La obra educativa del gobierno en 1940. Bogotá: Imprenta Nacional, 1940. 
Palomino, Delia. «Informe sobre el primer fondo bibliográfico de la sala de seguridad: los incunables». Bogotá, 21 de agosto 21 1984, Archivo BNC.

Quijano, José María. «Informe del Bibliotecario Nacional». En Memoria del Secretario de lo Interior y Relaciones Exteriores de los Estados Unidos de Colombia, al Congreso Federal de 1868, 2a. ed. Bogotá: Imprenta de la Nación, 1868.

Quiñones, Octavio. «Acta de entrega de los libros incunables de la Biblioteca Nacional». Bogotá, 22 de agosto de 1949, Archivo BNC.

Rivas Sacconi, Fernando. «Acta relativa a los incunables universales o clásicos de la Biblioteca Nacional». Bogotá, 21 de febrero de 1957, Archivo BNC.

Samper, Daniel. «Informe el director de la Biblioteca Nacional». En Memoria del ministro de Educación Nacional al Congreso de 1931. Tomo I. Bogotá: Imprenta Nacional, 1931.

Socorro, Manuel del. «Sigue el discurso empezado en el No. anterior». Papel periódico de la Ciudad de Santafé de Bogotá, Bogotá, 19 de agosto de 1796.

Tavera, Gonzalo. A. «Bosquejo descriptivo de la Biblioteca Nacional de Colombia». Anales de la Universidad XIII, nº 91 (1879).

Ungar, Hans. «Imprenta e Incunables: los Incunables de la Biblioteca Nacional». Gaceta XI, nº 19 (1978): 25-29.

Verasttegui, Antonio de y Francisco Antonio Moreno. Inventario de la Biblioteca Común del Colegio Máximo de la Compañía de Jesús. Santafé de Bogotá: Real Biblioteca de Santafé. 17661767.

Vergara, Francisco J. «Informe del director de la Biblioteca Nacional». En Informe que el ministro de Instrucción Pública presenta al Congreso de Colombia en sus secciones ordinarias de 1904. Bogotá: Imprenta Nacional, 1904. 


\section{Bibliografía}

Abad, Julián. Catálogo bibliográfico de la colección de incunables de la Biblioteca Nacional de España. Vol. I. Madrid: Biblioteca Nacional de España, 2010.

Biblioteca Luis Ángel Arango. Incunables de la Biblioteca Luis Ángel-Arango del Banco de la República. Bogotá: Litografía Arco, 1982.

Biblioteca Nacional de Colombia. «Incunables». Senderos I, n 5 (1934): 263-64. . «Nueva Serie de incunables». Senderos II, n 9 (1934): 180-84.

Carvajal, Juan, editor. Monstruos y prodigios en el Liber Cronicarum incunable de la biblioteca JPF de San José de Cúcuta. Cúcuta: Ediciones Heredita, [2008]?

. Rameras y esposas: en el Liber Cronicarum incunable de la biblioteca JPF de San José de Cúcuta. San José de Cúcuta: Ediciones Hederieta, [2010?].

Centro cultural de la Alcaldía de Cúcuta. Una mirada al libro Crónicas de Nuremberg, Incunable propiedad de la ciudad de Cúcuta. Cúcuta: Talleres Gráficos de La Opinión, 1998.

Checa, José Luis. El libro antiguo. Madrid: Acento Editorial, 1999.

Del Rey Fajardo, José. La biblioteca colonial de la Universidad Javeriana de Bogotá. Santafé de Bogotá: Pontificia Universidad Javeriana; San Cristóbal: Universidad Católica del Táchira, [2001].

Franco, María Victoria. Cinco incunables en la biblioteca general de la Universidad de los Andes. Bogotá: Universidad de los Andes, 1980.

Haebler, Konrad. Introducción al estudio de los incunables. Madrid: Ollero \& Ramos Editores, 1995. 
Hernández de Alba, Guillermo y Juan Carrasquilla Botero. Historia de la Biblioteca Nacional de Colombia. Bogotá: Publicaciones del Instituto Caro y Cuervo, 1977.

Knudsen, Hans-Peter, et. al. Tesoros del Colegio Mayor de Nuestra Señora del Rosario: 350 años. Bogotá: Villegas Editores, 2003.

Labarre, Albert. Historia del libro. México: Siglo XXI, 2002.

National Diet Library. "What are incunabula?». Acceso el 12 de mayo de 2015, http://www.ndl.go.jp/incunabula/e/chapter1/

Posada, Eduardo. Narraciones: capítulos para la historia de Bogotá. Bogotá: Librería Americana, 1906.

Restrepo, Jaime. La invención de la imprenta y los libros incunables. Bogotá: Universidad del Rosario, 2014.

Rubio, Alfonso. Libros antiguos en la Universidad del Valle. Cali: Programa Editorial Universidad del Valle, 2014.

Villegas, Benjamín, director. El libro de los libros: bibliotecas Pontificia Universidad Javeriana. Bogotá: Villegas Editores y Universidad Javeriana, 2010.

\section{Citar este artículo:}

López Arévalo, Robinson. "La colección de incunables de la Biblioteca Nacional de Colombia: tras las huellas y vacíos de su formación». Historia Y MEMORIA, n 13 (2016): 85-120. DOI: http://dx.doi.org/10.19053/20275137.5201 